\title{
Lacrimal gland carcinoma ex pleomorphic adenoma with chronic lymphocytic leukemia infiltration
}

This article was published in the following Dove Press journal:

Clinical Ophthalmology

7 October 2014

Number of times this article has been viewed

\author{
Rita Couceiro' \\ Cláudia Loureiro' \\ Pedro Luís ${ }^{2}$ \\ Dolores López-Presa ${ }^{2}$ \\ Helena Proença' \\ Ana Fonsecal \\ Manuel Monteiro-Grillo \\ 'Department of Ophthalmology, \\ Hospital de Santa Maria, Lisbon, \\ Portugal; ${ }^{2}$ Department of Pathology, \\ Hospital de Santa Maria, Lisbon, \\ Portugal
}

Correspondence: Rita Couceiro Avenida Professor Egas Moniz, Hospital Santa Maria, Secretariado do Serviço de Oftalmologia, I649-035 Lisboa, Portugal $\mathrm{Tel}+35$ I 913988901

$\mathrm{Fax}+35 I 217805653$

Email anaritacouceiro@gmail.com
Purpose: To report a rare case of lacrimal gland carcinoma ex pleomorphic adenoma (Ca ex PA) with chronic B-cell lymphocytic leukemia (B-CLL) infiltration in a patient without a previous diagnosis of B-CLL.

Patient and methods: We report a 66-year-old woman who presented with recent worsening of a long-standing right eye proptosis. Sequential orbital computed tomography imaging was performed over the course of 2 years, and biopsy specimens were analyzed.

Results: Initial computed tomography scans revealed a lacrimal gland lesion with stable dimensions for more than 1 year and no malignancy features on incisional biopsy. Subsequently, lesion volume growth and bone erosion were documented on orbital computed tomography. Lateral orbitectomy and lacrimal gland resection were performed. Pathology and immunohistochemistry detected $\mathrm{Ca}$ ex PA with B-CLL infiltration.

Conclusion: This case highlights the importance of persistent investigation of clinically suspicious orbital lesions. To our knowledge, this is the first description of a case of lacrimal gland Ca ex PA with B-CLL infiltration.

Keywords: ex pleomorphic adenoma, chronic lymphocytic leukemia, lacrimal gland malignancy, proptosis

\section{Introduction}

Carcinoma ex pleomorphic adenoma ( $\mathrm{Ca}$ ex PA) is the second most common primary epithelial malignancy of the lacrimal gland, ${ }^{1}$ representing $4 \%$ of all lacrimal gland lesions. ${ }^{2}$ It typically originates from spontaneous malignant transformation of a primary or recurrent pleomorphic adenoma (PA), which is a benign epithelial lacrimal gland lesion. ${ }^{1,2}$

In $\mathrm{Ca}$ ex PA, orbital computed tomography (CT) imaging generally shows an enlarged lacrimal fossa surrounded by early bone destruction, ${ }^{2}$ although these radiologic features are not exclusive to this type of tumor. Histologically, Ca ex PA shows characteristics of a PA with areas of malignant transformation; ${ }^{1,2}$ in most cases, these elements are poorly differentiated adenocarcinomas.

Only a minority of lacrimal gland tumors represent epithelial malignancies; most include lymphoproliferative disease, predominantly lymphomas. ${ }^{3}$ Leukemia may also infiltrate the orbit and adnexal tissues, usually presenting as slowly enlarging lesions. Direct infiltration of these tissues is more common in acute leukemia than in chronic lymphoproliferative disorders, but it may occur as the initial manifestation of chronic leukemia or develop during its course. ${ }^{4}$ 


\section{Case report}

A 66-year-old woman with a previous history of thyroid papillary carcinoma with extranodal dissemination, which was treated by thyroidectomy and radioactive iodine 22 years previously, presented with a long-standing proptosis of the right eye since her thyroid diagnosis, with progressive worsening over the past few months. Current thyroid hormonal blood testing was normal, and thyroid-stimulating hormone receptor antibodies were negative.

Ophthalmic examination revealed best corrected visual acuities of 20/20 bilaterally. Anterior segment and fundi were unremarkable in both eyes. External examination demonstrated inferior dystopia with eccentric proptosis of the right eye without pain on retropulsion and with little reducibility. Hertel exophthalmometer measurements $(100 \mathrm{~mm})$ were $24 \mathrm{~mm}$ on the right eye and $19 \mathrm{~mm}$ on the left eye. No limitation of ocular movements was noted, and the patient did not complain of diplopia at any point.

Orbital CT revealed a right intraorbital, extraconal lesion with regular borders in the lacrimal gland, causing slight proptosis and optic nerve stretching.

Lacrimal gland incisional biopsy identified scarce lymphoplasmacytic inflammatory infiltrates and some hyperplasia of glandular tissue, but no malignancy features. After careful consideration, taking the biopsy results into account as well as the absence of malignancy suspicion on CT imaging, we decided on close monitoring of the patient. She did not report further worsening of symptoms; however, a subsequent orbital CT scan performed 2 years after the patient was admitted to our institution revealed a substantial growth of the lacrimal gland lesion, showing internal heterogeneity and evidence of osteolysis of the lateral orbital wall with orbital remodeling (Figure 1A, B).

The patient underwent lateral orbitectomy and lacrimal gland resection with resolution of proptosis. New pathology and immunohistochemistry results revealed $\mathrm{Ca}$ ex PA, with a myoepithelial carcinoma element occupying $25 \%$ of total lesion volume. This myoepithelial carcinoma element showed immunoreactivity to vimentin, CK5/6, and smooth muscle actin antibody. In addition, pathology identified B-CLL lesion infiltration at the lesion's periphery, in continuity with the lesion itself (Figure 2), with a positive immunohistochemistry reaction to CD20, CD79a, CD5, $\mathrm{CD} 23, \mathrm{CD} 43$, and bcl-2 and a negative reaction to $\mathrm{CD} 3$ and cyclin D1.

White blood cell count was $20.80 \times 10^{9} / \mathrm{L}$, with $76 \%$ lymphocytes. Bone marrow was hypercellular, with 77\% lymphocytes, revealing morphologic and immunochemistry features of B-CLL. Hematologic and systemic evaluation determined a stage 1 B-CLL diagnosis, with multiple cervical and supraclavicular adenopathies identified in CT imaging. However, no treatment was warranted because of sustained clinical stability. One and a half years after the surgery, the patient's state remains clinically unchanged.

This case report was performed with informed consent regarding the consultation of human medical records.

\section{Discussion}

The differential diagnosis of lacrimal gland lesions includes a variety of neoplasms and related lesions. It is important to recognize that the lacrimal gland is the only tissue in the
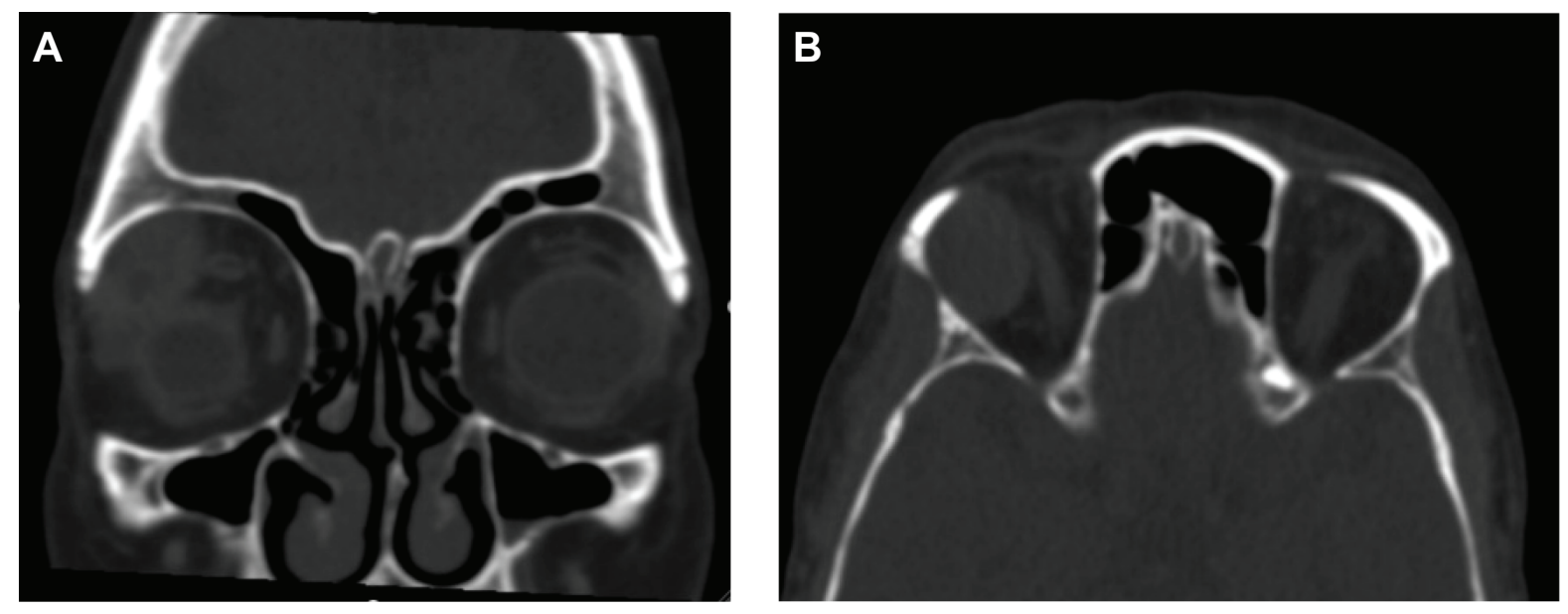

Figure I Orbital computed tomography.

Notes: (A) Coronal section. (B) Transverse section. Showing a mass lesion in the right lacrimal gland, with regular borders and internal heterogeneity, determining an inferior and medial deviation of orbital structures. 


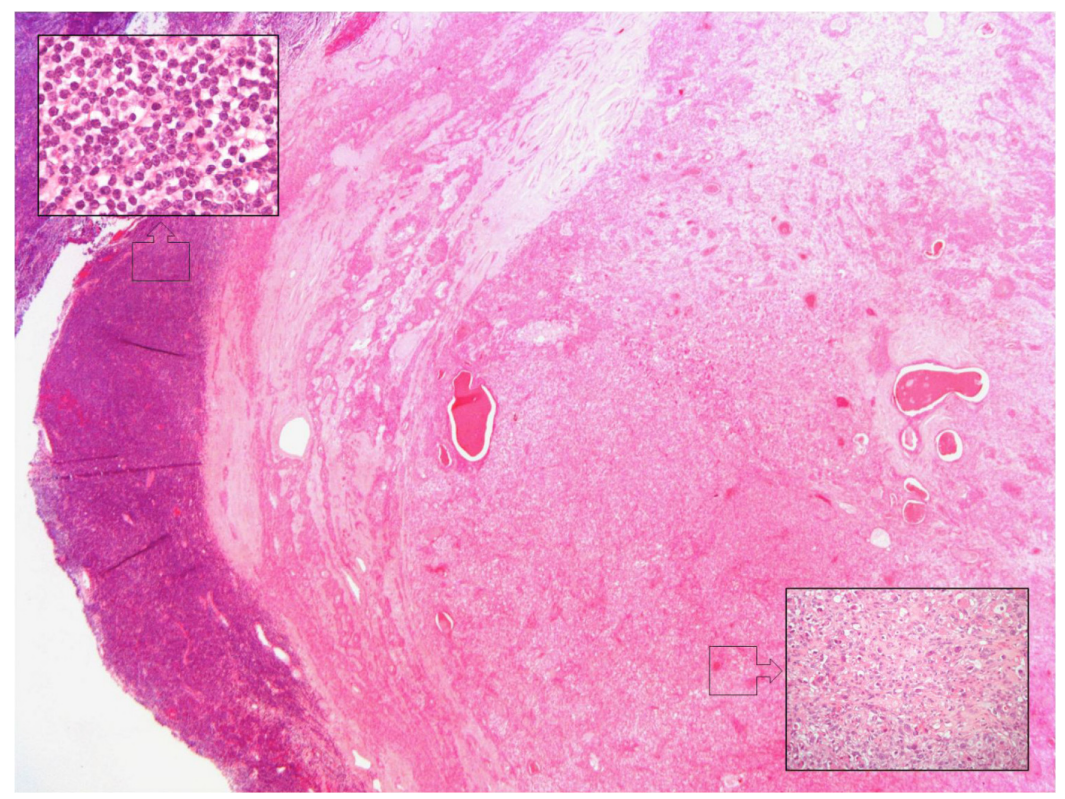

Figure 2 Pleomorphic adenoma with a malignant component of myoepithelial carcinoma (right inset).

Notes: Peripherally, there is infiltration by chronic lymphocytic leukemia/small lymphocytic lymphoma (left inset).

orbit containing epithelium and lymphoid tissue, ${ }^{1}$ which determines the type of neoplasms arising in that location.

In the reported case, the patient presented with a longstanding proptosis of her right eye, initially attributed to her thyroid disease. However, it is a valid assumption to presume that, at some point, a PA was present in the lacrimal gland and that it eventually suffered malignization. Indeed, malignization of long-standing, stable PA has been reported after periods as long as 60 years. ${ }^{1}$ Moreover, several authors suggest an increase in recurrence and malignization risk of PA after biopsy. ${ }^{1,5}$ Nevertheless, a 2009 review article by Lai et al concluded that it is no longer tenable to continue a strict "no-biopsy" policy for suspected lacrimal gland pleomorphic adenoma, stating that preoperative biopsy should be considered in all lacrimal gland mass lesions, including PA, and that management should be tailored to the biopsy findings. ${ }^{6}$

Therefore, we decided to initially perform an incisional biopsy, as the considerable growth of a long-standing lacrimal gland mass suggested malignancy, although imaging characteristics did not favor that possibility. Posteriorly, when lesion growth and bone erosion were documented on orbital CT, the patient was immediately submitted to lacrimal gland resection and lateral orbitectomy. We believe that the unremarkable incisional biopsy findings probably resulted from a nonrepresentative sample.

In this case, pathology and immunohistochemistry played a fundamental part, ultimately allowing for systemic diagnosis of B-CLL and identifying an uncommon malignization type of Ca ex PA (myoepithelial carcinoma).

We would like to highlight that B-CLL showed peritumoral infiltration, and not intratumoral infiltration, which makes it unlikely for the incisional biopsy to have caused it. Although a rare event, infiltration of the lacrimal gland by B-CLL can be the first sign of the disease, ${ }^{7}$ warranting hematologic and systemic evaluations to stage leukemia and determine proper management.

Numerous malignancies may arise in the lacrimal gland, and persistent investigation of clinically suspicious lesions is mandatory. Pathology and immunohistochemistry play important roles in determining a precise diagnosis of lacrimal gland malignancy and ultimately may allow for a systemic malignancy diagnosis. To our best knowledge, this is the first report of a case of lacrimal gland Ca ex PA with B-CLL infiltration.

\section{Acknowledgment}

We thank José Pimentel, MD, from the Neuropathology Laboratory, Hospital de Santa Maria, Lisbon, Portugal.

\section{Disclosure}

The authors report no conflicts of interest in this work.

\section{References}

1. Shields JA, Shields CL. Eyelid, Conjunctival and Orbital Tumors - An Atlas and Textbook: An Atlas and Textbook. 2nd ed. Philadelphia, PA: Lippincott Williams and Wilkins; 2008. 
2. Tovilla-Canales JL, Ball S, Olvera O, Martin FB. Diagnosis and treatment of lacrimal gland neoplasias: a better understanding of the nature of these tumors and advanced diagnostic technologies are improving management. Rev Ophthalmol. Epub 2013 Apr 5.

3. Hong WK, Bast RC, Hait WN, et al. Holland-Frei Cancer Medicine. 8th ed. Shelton, CT: People's Medical Publishing House; 2010.

4. Coelho H, Guerra M, Teixeira MA, Canelhas A, Pinto Ribeiro AC, Lima M. Bilateral orbital masses in a patient with B-cell chronic lymphocytic leukemia: a case report. Haematologica. 2007;88(4):46-47.
5. Rose GE, Wright JE. Pleomorphic adenoma of the lacrimal gland. Br J Ophthalmol. 1992;76(7):395-400.

6. Lai T, Prabhakaran VC, Malhotra R, Selva D. Pleomorphic adenoma of the lacrimal gland: is there a role for biopsy? Eye (Lond). 2009;23(1):2-6.

7. Hatton MP, Rubin PA. Chronic lymphocytic leukemia of the orbit. Arch Ophthalmol. 2002;120(7):990-991.

\section{Publish your work in this journal}

Clinical Ophthalmology is an international, peer-reviewed journal covering all subspecialties within ophthalmology. Key topics include: Optometry; Visual science; Pharmacology and drug therapy in eye diseases; Basic Sciences; Primary and Secondary eye care; Patient Safety and Quality of Care Improvements. This journal is indexed on

\section{Dovepress}

PubMed Central and CAS, and is the official journal of The Society of Clinical Ophthalmology (SCO). The manuscript management system is completely online and includes a very quick and fair peer-review system, which is all easy to use. Visit http://www.dovepress.com/ testimonials.php to read real quotes from published authors. 